\title{
Which do you want first: The good news or the good news?
}

\author{
Leonard N. Girardi, MD
}

From the Department of Cardiothoracic Surgery, Weill Cornell Medical College, New York, NY.

Disclosures: Author has nothing to disclose with regard to commercial support.

Received for publication Aug 3, 2015; accepted for publication Aug 5, 2015; available ahead of print Aug 28, 2015.

Address for reprints: Leonard N. Girardi, MD, Department of Cardiothoracic Surgery, Weill Cornell Medical College, New York, NY 10021 (E-mail: lngirard@med.cornell.edu).

J Thorac Cardiovasc Surg 2015;150:1148-9

$0022-5223 / \$ 36.00$

Copyright (c) 2015 by The American Association for Thoracic Surgery

http://dx.doi.org/10.1016/j.jtcvs.2015.08.011

In total aortic arch replacement, the specter of stroke remains the major concern to patients in need of surgery and the surgeons performing these high-risk operations. With improvements in cardiopulmonary bypass, surgical technique, postoperative care, and neurologic protection, the mortality associated with elective complex arch reconstruction has decreased precipitously. However, the risk of permanent neurologic deficit (PND) remains approximately $5 \%{ }^{1}$ Irrespective of perfusate temperature (moderate vs profound hypothermia) or type of adjunctive cerebral protection (antegrade vs retrograde vs none), meaningful differences in outcome have yet to be ascribed to one technique over another regardless of whether the data come from small prospective trials or large meta-analyses of thousands of patients. In this issue of the Journal, Svensson and colleagues ${ }^{2}$ have made a valiant attempt to sort out this dilemma by enrolling a small cohort of patients undergoing open total arch reconstruction in a prospective, randomized trial comparing profound hypothermia with antegrade or retrograde cerebral protection as an adjunct. By using a combination of clinical assessment, brain imaging, and neurocognitive testing, have they succeeded in convincing those of us performing this surgery that one method of brain protection is better than another? Have they identified the ideal method to assess neurologic injury?

The difficulty in interpreting the data in this study is both good news for the patients but bad news for the scientists. As the authors point out, the study was underpowered to detect differences in cerebral protection strategy because the results from this experienced center were considerably better than anticipated when performing their initial power calculations. An operative mortality of $0.8 \%$ for 121 total arch reconstructions is not only admirable but also a benchmark to which all aortic surgeons aspire. A similar rate of PND is also enviable but, fortunately for the patients, fairly representative of the current state of the art for arch surgery in high-volume centers with experienced teams caring for the patients perioperatively. ${ }^{3}$

Although the addition of brain imaging and neurocognitive testing provided a more complete evaluation of neurologic

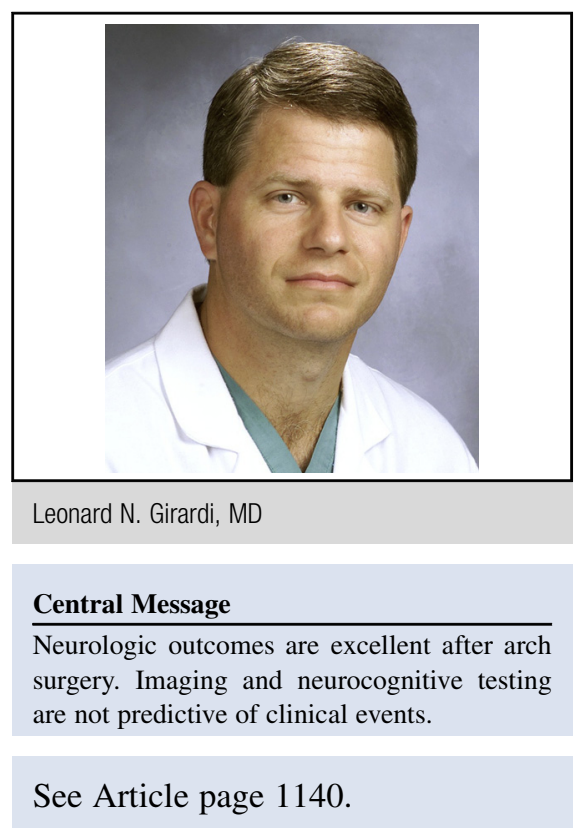

injury, neither predicted the immediate outcome of the procedure or the ability of those with early deficits to recover. Unfortunately, $4.8 \%$ of the patients had a decline in performance on repeat neurocognitive testing 6 months after surgery. However, 5.5\% showed improvement and approximately $90 \%$ had a stable assessment over a battery of 13 tests designed to examine everything from attention to memory to timed manual dexterity. Although they correctly point out that improved performance on repeat neurocognitive testing may be due to a learning effect, that recoverable ability to learn should be somewhat reassuring and is not dissimilar to findings previously presented on patients having profound hypothermia alone as the sole method of cerebral protection for arch surgery. ${ }^{4}$

So what have we learned and where do we go from here? What is clear is that we have made great strides in protecting patients from neurologic injury when undergoing arch reconstruction. Few have PND, and those with radiographic or neurocognitive evidence of subtle change have higher integrative function that is mostly unaffected 6 months later. The authors are correct in stating that future studies for cardiovascular procedures with a high potential for cerebrovascular injury should include all 3 methods used in this study. However, before we implicate missed neurologic events as harbingers of late dementia, it is imperative that we obtain long-term neurologic follow-up and develop more sophisticated tools to correlate diffusion-weighted magnetic resonance imaging with clinically relevant events. 


\section{References}

1. Okita Y, Miyata H, Motomura N, Takamoto S, Japan Cardiovascular Surgery Database Organization. A study of brain protection during total arch replacement comparing antegrade cerebral perfusion versus hypothermic circulatory arrest, with or without retrograde cerebral perfusion: analysis based on the Japan Adult Cardiovascular Surgery Database. J Thorac Cardiovasc Surg. 2015;149(2 Suppl):S65-73.

2. Svensson LG, Blackstone EH, Apperson-Hansen C, Ruggieri PM, Ainkaran P, Naugle RI, et al. Implications from neurologic assessment of brain protection for total arch replacement from a randomized trial. J Thorac Cardiovasc Surg. 2015;150:1140-7.e11.

3. Girardi LN, Shavladze N, Sedrakyan A. Safety and efficacy of retrograde cerebral perfusion as an adjunct for cerebral protection during surgery on the aortic arch. $J$ Thorac Cardiovasc Surg. 2014;148:2927-33.

4. Chau KH, Friedman T, Tranquilli M, Elefteriades JA. Deep hypothermic circulatory arrest effectively preserves neurocognitive function. Ann Thorac Surg. 2013; 96:1553-9. 